http://journal.nafo.int

J. Northw. Atl. Fish. Sci., Vol. 19: 41-49

\title{
Analysis of Subsampled Catches from Trouser Trawl Size Selectivity Studies
}

\author{
N. G. Cadigan \\ Department of Fisheries and Oceans, Science Branch \\ Northwest Atlantic Fisheries Centre, P. O. Box 5667 \\ St. John's, Newfoundland, Canada A1C 5X1 \\ and \\ D. L. Boulos and W. M. Hickey \\ Department of Fisheries and Oceans, Fisheries Habitat and Management Branch \\ P. O. Box 5667, St. John's, Newfoundland, Canada A1C 5X1
}

\begin{abstract}
An analysis of a trouser trawl experiment with multiple subsampled hauls is presented. The standard method of analysis involves scaling catches by subsampling fractions and combining the catches for each haul to obtain an estimate of the size selectivity of the test gear. This procedure results in invalid statistical inferences and is not appropriate if the split of fish is not the same in all hauls or if subsampling fractions have measurement error. Modifications of the selectivity model are proposed that significantly improve the analysis of this type of data (e.g. to estimate selectivity without subsampling fractions). Likelihood ratio tests are developed to test which modified selectivity model best fits the data. Confidence bounds are developed as diagnostic tools. The procedures are illustrated with a data analysis.
\end{abstract}

Key words: Gear selectivity, statistical methods, trawl

\section{Introduction}

A size selectivity study involves estimating the catch efficiency of a fishing gear. The trouser trawl is one method that has been developed for this purpose. This trawl contains both experimental and control mesh codends that are separated so that the selectivity of the experimental mesh can be determined through a comparison of catches from this mesh and the control mesh. A description of the trouser trawl is given in Cooper and Hickey (1989) and Walsh et al. (1992). The trouser trawl was developed as an alternative procedure to the covered codend and alternate haul methods and came into widespread use in Canada in the mid-1980s when researchers began observing the covered codend with underwater cameras and discovered severe masking of the codend mesh by the cover, and also when the alternate haul method was found to require too many sets for valid comparisons. However, the trouser trawl has one major disadvantage in that the codends may enounter different amounts of fish.

Selectivity curves have, in the past, been estimated from trouser trawl data by eye or by scaling the data for a logistic regression analysis (Pope et al., 1975). These procedures were found to be unsatisfactory for several reasons (e.g. unevenness in warps or bridle lengths cause unequal fishing for the two sections of the trouser trawl, species like plaice often enter a trawl more on one side than the other, etc.) and resulted in Millar (1992) (also Millar and Walsh, 1992) proposing a more rigorous statistical methodology that essentially works by conditioning on the total catch in both the experimental (large mesh) and control (small mesh) codends for each size or length-class of fish measured. The method has been shown by Cadigan and Millar (1992) to be superior to other methods. Millar (MS 1991) has shown that the method is applicable for a variety of size selectivity studies and has called it SELECT (Share Each Length class's Catch Total).

Subsampling of catches is usually carried out in experiments of this type whenever catches are large. The sampling procedure varies according to the conditions encountered on the vessel, such as weather, volume of fish, space for sampling, and manpower available. If the catches are not too large, one procedure is to place the fish in boxes, then randomly select the appropriate number to sample. The average weight per box is combined with the total number of boxes to give the total weight of the catch. If the catches are very large, then due to time constraints only a fixed portion of the total catch (independent of length) is sampled. In this case the total weight is estimated from the total gutted weight or visually when no other alternative is available. 
The purpose of this paper is to extend the Millar and Walsh (1992) procedures to the analysis of subsampled selectivity data. SELECT is shown to be appropriate for the analysis of one subsampled haul but not for a combination of multiple subsampled hauls unless the sampling fractions are the same. The current practice is to scale the data from each haul according to subsampling effort (e.g. Suuronen and Millar, 1992), however, the standard errors of parameter estimates and the estimated selectivity curves may be incorrect in doing so. A more rigorous procedure is proposed that is free of these deficiencies. Methods and modifications for subsampling are developed here in terms of the trouser trawl and a fish species, however, applications to other selectivity experiments are straightforward.

\section{Methods}

\section{SELECT for a subsampled sampled haul}

The statistical modelling essentially follows Millar and Walsh (1992) and Millar (1992). We assume the split is unknown, however, Millar and Walsh (1992) considered the case where $p$ is assumed to be 0.5 . The split refers to the proportion (p) of fish that enter the experimental codend relative to the total number of fish entering either codend.

Let $N_{11}$ and $N_{12}$ be random variables representing the number of fish of length class I sampled in the experimental and control codends respectively. Let $\lambda_{\text {I }}$ be the number of length I fish entering the trawl and let $f_{1}$ and $f_{2}$ denote the subsampling fractions of the experimental and control codends respectively. The subsampling fraction is the subsampled weight divided by the total weight in the codend and is assumed to be equivalent to the fraction of numbers at length sampled. If the retention probability of length I fish in the experimental codend is denoted as $r_{1}$ and all fish that enter the control codend are caught then the expectations of $\mathrm{N}_{11}$ and $\mathrm{N}_{12}$ are:

$$
\begin{aligned}
& E\left(N_{\mid 1}\right)=f_{1} \operatorname{pr} \lambda_{1}, \\
& E\left(N_{\mid 2}\right)=f_{2}(1-p) \lambda_{1} .
\end{aligned}
$$

If $\mathrm{N}_{11}$ and $\mathrm{N}_{12}$ are considered as Poisson random variables then, conditional on the observation of $\mathrm{N}_{11}+\mathrm{N}_{12}$ (denoted as $\mathrm{n}_{11}+\mathrm{n}_{12}$ ), $\mathrm{N}_{11}$ is distributed as a Binomial random variable. The expected number of length I fish sampled in the experimental codend if $n_{1+} \phi_{l} l$ where,

$$
\phi_{I}=\frac{f_{1} p r_{1}}{f_{2}(1-p)+f_{1} p r_{1}}
$$

and $n_{1+}=n_{11}+n_{12}$.

The loglikelihood (log of the likelihood of the data given the parameters and the binomial model) is specified in terms of the canonical parameter $\left(\theta_{\mid}\right)$ of $\mathrm{N}_{11}$ (see McCullagh and Nelder, 1989, p. 30). Let $\Lambda$ equal the loglikelihood, then; apart form a constant;

$$
\Lambda=\sum_{\mid=1_{0}}^{L}\left\{n_{\mid 1} \theta_{\mid}-n_{I}+\log \left(1+\exp \left(\theta_{\mid}\right)\right)\right\},
$$

where $I_{0}$ and $L$ are the minimum and maximum length classes observed and $\theta_{1}=\log \left(f_{1} / f_{2}\right)+\log (p /$ $(1-p))+\log \left(r_{p}\right)$

The function $r_{1}$, which is the selection of the experimental gear, is commonly taken as the logistic function:

$$
r_{1}=\frac{\exp (a+b l)}{1+\exp (a+b l)}
$$

Let $\beta^{\prime}=[a, b, p]$ be the vector of parameters to estimate. Maximum likelihood estimates of $\beta$ are obtained by finding the roots of $\partial \Lambda / \partial \beta$ using iterative reweighted least squares (Millar, 1992). Let $W$ be the $m \times m$ diagonal matrix where $m=L_{-} I_{0+1}$ and the ith diagonal element of $W$ is $n_{\mid}+\phi_{\mid}\left(1-\phi_{\mid}\right)$. Let $X$ be the $\mathrm{m} \times 3$ matrix whose Ith row is given by $\partial \theta_{\mu} / \partial \beta^{\prime}$. The large sample covariance matrix of the maximum likelihood estimate of $\beta$ is the inverse of $E\left(-\partial^{2} \Lambda / \partial \beta \partial \beta^{\prime}\right)=X^{\prime} W X$. A statistical test based on the likelihood ratio may be used to test if $p=1 / 2$. If $\Lambda_{0}$ is the loglikelihood obtained by fitting the model $\theta_{1}=\log \left(f_{1} / f_{2}\right)+\log \left(r_{1}\right), \quad\left(e . g . \quad p_{0}=1 / 2\right.$ then $2\left(\Lambda-\Lambda_{0}\right)$ is distributed asymptotically as a chisquare random variable with 1 degree of freedom where the unknown parameters in $\Lambda$ and $\Lambda_{\circ}$ are replaced by their maximum likelihood estimates. If $2\left(\Lambda-\Lambda_{0}\right)$ exceeds 4 then that is evidence that $p \neq$ $1 / 2$.

If we write:

$$
p^{*}=\frac{f_{1} p}{f_{2}(1-p)+f_{1} p},
$$

then (1) may be rewritten as:

$$
\theta_{1}=\frac{p^{*} r_{1}}{\left(1-p^{*}\right)+p^{*} r_{1}}
$$

which is identical to the model in Millar and Walsh (1992); hence, standard software such as in Millar and Cadigan (1991) can be used to estimate selectivity from subsampled hauls without information on the subsampling fractions. However, p must be interpreted in terms of $p^{*}$ and not the split of fish. This procedure is only appropriate if the subsampling fractions are the same for all fish in each codend. If fish are subsampled differentially (say by length) then at least the relative 
subsampling fractions will be needed for use with a modification of (1).

Another procedure that is commonly used for subsampled data is to either scale the numbers sampled in:

i) the experimental codend down so that $f_{\mathrm{k} 1}$ $=f_{\mathrm{k} 2}$ (Suuronen and Millar, 1992), or

ii) the control codend up so that $f_{\mathrm{k} 1}=f_{\mathrm{k} 2}$.

Both methods will produce the same parameter estimates, however, the standard errors of parameter estimates will either be too large using (i) or too small using (ii). Another difficulty with scaling is that if length I fish are caught in only one codend then the proportion retained remains the same even after adjustment. The scaling approach can lead to a differential adjustment of the proportions retained in the experimental codend while (1) suggests an adjustment for all lengths is required. There is no good reason why data should be scaled so we recommend not to do so.

\section{SELECT for subsamples from multiple hauls}

Consider a selectivity experiment consisting of $\mathrm{K}$ hauls. The notation used is modified by introducing $\mathrm{k}$ which indexes the $\mathrm{kth}$ haul, $\mathrm{k}=1, \ldots, \mathrm{K}$. For example, $p_{k}$ is the proportion of the total catch in haul $\mathrm{k}$ that is caught in the experimental codend. Start, as with a single haul experiment, by defining:

$$
\begin{aligned}
& E\left(N_{k 11}\right)=f_{k 1} p_{k} r_{k} \lambda_{k 1}, \\
& E\left(N_{k l 2}\right)=f_{k 2}\left(1-p_{k}\right) \lambda_{k 1},
\end{aligned}
$$

The $\lambda_{\mathrm{kl}}$, (nuisance) parameters are removed in the single haul experiment by conditioning on $\mathrm{n}_{\mathrm{kl}}$. Combining multiple hauls and dividing by the totals will remove the nuisance parameters only if the following conditions are met (for all k):

1. $r_{k l}$ 's are equal,

2. $p_{k}{ }^{\prime}$ s are equal, and

3. $f_{\mathrm{k} 1}=f_{\mathrm{k} 2}$.

Otherwise the $\lambda_{\mathrm{kl}}$ 's must all be equal which is an unreasonable assumption.

Fryer (1991) and Suuronen and Millar (1992) have proposed procedures to estimate a common selectivity when the first assumption does not hold; we simply test this assumption in the data analysis using standard likelihood theory. We also test assumption 2 and develop a procedure for estimating selectivity from multiple hauls with different splits. The last condition is rarely valid (except for full sampled multiple hauls) and is not assumed here.
The procedure is basically the same as before, except that the model for the proportion of fish sampled from the experimental codend in the kth haul is:

$$
\phi_{k l}=\frac{f_{k l} p_{k} r_{k l}}{f_{k 2}\left(1-p_{k}\right)+f_{k l} p_{k} r_{k l}} \text {. }
$$

The loglikelihood is:

$$
\sum_{k=1}^{K} \sum_{==1}^{L}\left\{n_{k \mid 1} \theta_{k l}-n_{k l+} \log \left(1+\exp \left(\theta_{k l}\right)\right)\right\},
$$

where $\theta_{k l}=\log \left(f_{k 1} / f_{k 2}\right)+\log \left(p_{k} /\left(1-p_{k}\right)\right)+\log \left(r_{k l}\right)$. That is, each haul is analyzed individually. Call this model A.

We test for constant selectivity (model B) by fitting the reduced model: $r_{1 \mid}=r_{2 \mid}=\ldots=r_{K I}$ for $\mathrm{I}=$ $\mathrm{I}_{0}, \ldots, \mathrm{L}$. The likelihood ratio procedure is again used to compare the full and reduced models, where twice the difference in loglikelihoods is distributed as a chi-square random variable with $2(K-1)$ degrees of freedom. Similarly, we test for a constant split and selectivity (model $\mathrm{C}$ ) by fitting the reduced model: $r_{11}=r_{2 l}=r_{K l}$ and $p_{1}=p_{2}=\ldots=p_{K}$, for $\mid=$ $\mathrm{I}_{\mathrm{o}}, \ldots, \mathrm{L}$. The likelihood ratio test statistic has $3(\mathrm{~K}-1)$ degrees of freedom.

Note that if we let:

$$
p_{k}^{*}=\frac{f_{k 1} p_{k}}{f_{k 2}\left(1-p_{k}\right)+f_{k 1} p_{k}},
$$

then:

$$
\phi_{k l}=\frac{p_{k}^{*} r_{k l}}{1-p_{k}^{*}+p_{k}^{*} r_{k l}} \text {. }
$$

Hence, it is possible to estimate a constant selectivity from multiple subsampled hauls without subsampling fractions using model B.

Standard errors of parameter estimates for model $A$ are obtained by using the formula in the previous section; that is, estimate $a, b$ and $p$ and compute X'WX for each haul. Standard errors for models $B$ and $C$ can be computed as follows (also for model $A$ ). Redefine $X$ as:

$$
X=\left[\begin{array}{c}
X_{1} \\
X_{2} \\
\cdot \\
X_{K}
\end{array}\right],
$$

where the Ith row of $X_{k}=\partial \theta_{k l} / \partial \beta^{* \prime}{ }_{k}$ and $\beta_{k}^{* \prime}=\left[a_{k}, b_{k}, p_{k}\right]$. Similarly, let: 


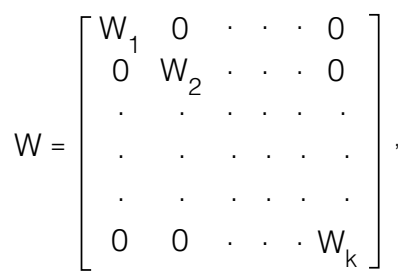

and $\beta^{* \prime}=\left[\beta^{* \prime}{ }_{1}, \ldots, \beta_{k}^{* \prime}\right]$. Redefine $\beta$ as:

$$
\beta^{\prime}=\left\{\begin{array}{cc}
{\left[a_{1}, b_{1}, p_{1}, \ldots, a_{k}, b_{k} p_{k}\right]} & \text { for model } A \\
{\left[a, b, p_{1}, \ldots, p_{k}\right]} & \text { for model } B \\
{[a, b, p],} & \text { for model } C
\end{array}\right.
$$

and let $G=\partial \beta^{*} / \partial \beta^{\prime}$. The covariance matrix for the maximum likelihood estimate of $\beta$ is the inverse of $-G^{\prime} X^{\prime} W X G$.

\section{Confidence bounds on selectivity curves}

If the likelihood ratio tests for constant selectivity or constant splits between hauls fail, then it is naturally interesting to determine which haul(s) differ in terms of selectivity or splits. The splits are scalars so standard multiple comparison procedures may be used. Determining which hauls have significantly different selectivity curves is more difficult. Scalar characterizations of the selectivity curves such as the $50 \%$ retention length could be used with standard multiple comparison procedures, however, such methods will obviously have low power. A better procedure is to plot the estimated selectivity curve with a confidence interval from model $\mathrm{B}$ or model $\mathrm{C}$ and overlay the $\mathrm{K}$ selectivity curves from model $A$. In most situations it should be clear which hauls have significantly different selectivity, although the estimated selectivity curve for all hauls will be "contaminated" by the hauls with different selectivity (e.g. the hauls with different selectivity will tend to mask themselves in models $\mathrm{B}$ or $\mathrm{C}$ ).

We construct confidence intervals for each point on a selectivity curve, and we use "Scheffè's procedure" (see, for example, Graybill (1976), pg. 197-198) to control the overall significance level. We assume the null model is correct and that parameter estimates are normally distributed to compute confidence bounds for $r$, such that the probability that the true selectivity exceeds the bounds at least once is at most $\alpha$ ( $\alpha$ is the significance level). The confidence bounds are constructed as follows: Let $\beta_{1}^{\prime}=[a, b]$ and let $V$ be the $2 \times 2$ covariance matrix of the maximum likelihood estimates of $\hat{\beta}_{1}$ (denoted as $\beta_{1}$ ). Then:

$$
\operatorname{Prob}\left[\left(\hat{\beta}_{1}-\beta_{1}\right)^{\prime} \mathrm{V}^{-1}\left(\hat{\beta}_{1}-\beta_{1}\right) \leq \chi^{2} \alpha(2)\right]=1-\alpha
$$

where $\chi_{\alpha(2)}^{2}$ is the $(1-\alpha)$ th quantile of the chisquare distribution with 2 degrees of freedom. Also,

$$
\begin{aligned}
& \operatorname{Prob}\left[\max _{h \neq 0} \frac{\left(h^{\prime}\left(\hat{\beta}_{1}-\beta_{1}\right)\right)^{2}}{h^{\prime} \operatorname{Vh}} \leq \chi^{2} \alpha(2)\right]=1-\alpha . \\
& \text { Let } d=\sqrt{h^{\prime} \operatorname{Vh} \chi^{2} \alpha(2), \text { then }} \\
& \operatorname{Prob}\left[h^{\prime} \hat{\beta}_{1}-d \leq h^{\prime} \beta_{1} \leq h^{\prime} \hat{\beta}_{1}+d\right] \geq 1-\alpha
\end{aligned}
$$

for any $h \neq 0$. If $h^{\prime}=[1,1]$ then:

$\operatorname{Prob}\left[\frac{\exp (a+b l-d)}{1+\exp (a+b l-d)} \leq r_{1} \leq \frac{\exp (a+b l+d)}{1+\exp (a+b l+d)}\right] \geq 1-\alpha$

The lower and upper bounds in the probability expression give the simultaneous confidence bounds for the selectivity function $r_{\mid}$. These bounds have at least $1-\alpha$ coverage for any or all points on the selectivity curve.

\section{Data}

A selectivity study for Atlantic cod, Gadus morhua, using nominal $135 \mathrm{~mm}$ square mesh was conducted in NAFO Div. $2 \mathrm{~J}+3 \mathrm{KL}$ during February 1992, using a $52 \mathrm{~m}$ commercial stern trawler. A 47 $\mathrm{mm}$ Hampijhan trawl was converted to a trouser trawl with a vertical divider panel and twin codends. The footrope length was $61 \mathrm{~m}$ and the headline length was $47 \mathrm{~m}$. The mesh size was $135 \mathrm{~mm}$ (k.c.) in the wings, square and first belly, and $135 \mathrm{~mm}$ in the twin extensions.

Five hauls were performed with this trawl and sampling was carried out by two fisheries representatives. Samples were obtained on deck where possible, however, sampling was carried out on the ramp when temperatures were below freezing. Fish lengths were measured to the nearest centimetre. The data are presented in Table 1.

\section{Results}

Parameter estimates, standard errors and some estimates of retention lengths are presented in Table $2 \mathrm{a}, 2 \mathrm{~b}$ and $2 \mathrm{c}$ for model $\mathrm{A}, \mathrm{B}$ and $\mathrm{C}$. The likelihood ratio test statistic of model $B$ versus $A$ (test for a common selectivity but haul specific splits) is 48.67. The 95th percentile of a chi-square statistic with 8 degrees of freedom is 15.507 so the conclusion from this test is that selectivity is not constant among hauls. The likelihood ratio test statistic of model $C$ versus $B$ (test for a common selectivity and 
TABLE 1. Data for the trouser trawl experiment investigating the selectivity for cod of a $135 \mathrm{~mm}$ square mesh trawl. $n_{k \| l}$ and $n_{k 12}$ are the numbers at each length class (I) caught in the experimental and control codends of the k'th haul. The fraction subsampled (fs) is in the last row.

\begin{tabular}{|c|c|c|c|c|c|c|c|c|c|c|}
\hline Length-class & $n_{711}$ & $\mathrm{n}_{712}$ & $n_{9 \mid 1}$ & $\mathrm{n}_{9 \mid 2}$ & $n_{1311}$ & $n_{1312}$ & $\mathrm{n}_{1411}$ & $n_{14 / 2}$ & $n_{1511}$ & $n_{1512}$ \\
\hline 26 & - & - & - & - & - & - & - & 1 & - & - \\
\hline 27 & - & - & - & - & - & - & - & 1 & - & - \\
\hline 28 & - & - & - & - & - & - & - & 2 & - & - \\
\hline 29 & - & - & - & - & - & - & - & 5 & - & - \\
\hline 30 & - & - & - & 2 & - & 2 & - & 5 & - & 1 \\
\hline 31 & - & - & - & 4 & - & 4 & - & 7 & - & 1 \\
\hline 32 & - & - & - & 5 & - & 5 & - & 7 & - & 5 \\
\hline 33 & - & 1 & - & 7 & - & 7 & - & 8 & - & 8 \\
\hline 34 & - & 3 & - & 12 & - & 12 & - & 16 & 1 & 12 \\
\hline 35 & - & 3 & 1 & 18 & - & 18 & - & 14 & - & 15 \\
\hline 36 & - & - & 1 & 22 & - & 22 & - & 15 & 4 & 8 \\
\hline 37 & - & 10 & - & 26 & 1 & 26 & - & 21 & 3 & 23 \\
\hline 38 & - & 9 & - & 22 & 1 & 22 & - & 28 & 4 & 24 \\
\hline 39 & 2 & 15 & 5 & 28 & 2 & 28 & 1 & 35 & 8 & 32 \\
\hline 40 & 1 & 20 & 6 & 35 & 4 & 35 & - & 41 & 7 & 30 \\
\hline 41 & 1 & 24 & 13 & 31 & 7 & 31 & 3 & 45 & 6 & 36 \\
\hline 42 & 2 & 21 & 14 & 39 & 7 & 39 & 2 & 35 & 16 & 38 \\
\hline 43 & 10 & 24 & 15 & 37 & 6 & 37 & 1 & 29 & 17 & 29 \\
\hline 44 & 5 & 25 & 31 & 29 & 14 & 29 & 8 & 30 & 8 & 20 \\
\hline 45 & 5 & 20 & 26 & 20 & 11 & 20 & 9 & 28 & 16 & 23 \\
\hline 46 & 13 & 20 & 22 & 25 & 15 & 25 & 10 & 22 & 15 & 20 \\
\hline 47 & 9 & 22 & 17 & 13 & 12 & 13 & 6 & 19 & 20 & 20 \\
\hline 48 & 13 & 27 & 24 & 15 & 13 & 15 & 7 & 14 & 15 & 12 \\
\hline 49 & 17 & 18 & 26 & 10 & 18 & 10 & 18 & 12 & 20 & 11 \\
\hline 50 & 12 & 8 & 23 & 10 & 17 & 10 & 11 & 13 & 13 & 6 \\
\hline 51 & 21 & 16 & 16 & 9 & 14 & 9 & 21 & 6 & 20 & 9 \\
\hline 52 & 30 & 9 & 17 & 9 & 20 & 9 & 25 & 14 & 13 & 7 \\
\hline 53 & 27 & 7 & 21 & 2 & 15 & 2 & 23 & 3 & 19 & 4 \\
\hline 54 & 20 & 9 & 16 & 3 & 14 & 3 & 24 & 2 & 18 & 4 \\
\hline 55 & 22 & 8 & 22 & 5 & 21 & 5 & 18 & 6 & 14 & 3 \\
\hline 56 & 17 & 4 & 26 & 4 & 17 & 4 & 27 & 3 & 19 & 3 \\
\hline 57 & 15 & 4 & 14 & 1 & 15 & 1 & 23 & 4 & 16 & 4 \\
\hline 58 & 17 & 6 & 12 & 3 & 15 & 3 & 14 & 6 & 9 & 4 \\
\hline 59 & 15 & 4 & 12 & 1 & 16 & 1 & 21 & 3 & 13 & 4 \\
\hline 60 & 10 & 1 & 9 & - & 8 & - & 10 & 1 & 5 & 1 \\
\hline 61 & 10 & 1 & 3 & - & 7 & - & 18 & 1 & 8 & 1 \\
\hline 62 & 11 & 4 & 4 & 1 & 4 & 1 & 11 & 1 & 3 & 0 \\
\hline 63 & 8 & 2 & 5 & - & 6 & - & 9 & - & 5 & - \\
\hline 64 & 6 & 2 & 4 & 1 & 2 & 1 & 10 & - & 1 & - \\
\hline 65 & 3 & 1 & - & - & 6 & - & 7 & - & 2 & - \\
\hline 66 & 3 & 1 & 1 & 1 & 3 & 1 & 5 & 1 & 2 & - \\
\hline 67 & - & 1 & 1 & - & 2 & - & 1 & - & 2 & - \\
\hline 68 & 3 & - & - & 1 & 1 & 1 & 2 & - & - & 1 \\
\hline 69 & - & - & - & - & 1 & - & - & - & - & 1 \\
\hline 70 & 1 & - & - & - & 1 & - & 1 & - & - & - \\
\hline 71 & - & - & 1 & - & 1 & - & 1 & - & - & - \\
\hline 72 & 1 & - & - & - & - & - & - & - & - & - \\
\hline 73 & 3 & - & - & - & - & - & 1 & - & - & - \\
\hline 74 & - & 1 & - & - & - & - & - & - & - & - \\
\hline 76 & 1 & - & - & - & - & - & - & - & - & - \\
\hline 77 & - & - & - & - & 1 & - & 1 & - & - & - \\
\hline 80 & 1 & - & - & - & - & - & - & - & - & - \\
\hline 81 & 1 & - & - & - & - & - & - & - & - & - \\
\hline 83 & - & 1 & - & - & - & - & - & - & - & - \\
\hline Totals & 336 & 352 & 408 & 451 & 318 & 451 & 349 & 504 & 342 & 420 \\
\hline$f^{\prime} s$ & 0.70 & 0.16 & 0.28 & 0.02 & 0.10 & 0.03 & 0.59 & 0.06 & 0.29 & 0.03 \\
\hline
\end{tabular}


split versus a common selectivity but haul specific splits) is 110.92. The 95th percentile of a chi-square statistic with 4 degrees of freedom is 9.45 so the conclusion from this test is that the split is not constant among hauls.

In Table 2 a note that the split for haul 9 (0.33) and haul 13 (0.76) appear different to the split in hauls 7,14 and 15 (roughly 0.5) and these hauls likely lead to the rejection of the likelihood ratio test of model $\mathrm{C}$ versus $\mathrm{B}$. It is not as clear which hauls have statistically different selectivities. Hauls 7 and 9 have greater $50 \%$ retention lengths than the other hauls do, however, haul 15 had a greater selection range. Figure 1 presents a better picture of the between haul variation in selectivity. The estimated selectivities from models B and C (with 95\% confidence bounds) are plotted as lines and the estimated selectivities from model $A$ are plotted as points. The selectivity from all individual hauls except 7 and 13 exceed the confidence bounds of the joint selectivity from models B or C. It appears that selectivity varies in a random manner for each haul, although more so for haul 9. The selectivity estimated from models $\mathrm{B}$ and $\mathrm{C}$ are nearly identical; there is only a small increase in variance as the result of estimating haul specific splits (model $B$ ). This suggests that the analyses of subsampled catches with imperfect or no subsampling fractions is a feasible procedure (recall that model $\mathrm{B}$ can be used to estimate a common selectivity from multiple subsampled hauls without using subsampling fractions).

Pearson residuals (McCullagh and Nelder, 1989) are plotted for each haul and model in Fig. 2. They are a good tool to assess model fits. The residuals from model $B$ (middle column) for hauls 9,14 and 15 are clearly not homogeneously distributed within \pm 2 as we would expect if the assumption that selectivity is the same in each haul were correct. Also, the residuals from model $\mathrm{C}$ and haul 13 are mostly positive. This is because the split appears to be much larger than the splits in other hauls. The same pattern occurs for haul 9 (split $<<0.5)$ except that the residuals are mostly negative. The residual plots from model $A$ and hauls 13 and 14 also suggest that the selectivity model may not hold for all lengths of fish caught because of the systematic pattern in the residuals for fish up to $40 \mathrm{~cm}$ (perhaps because selectivity is not logistic in form).

TABLE. 2A. Parameter estimates and standard errors (in parentheses) for cod size selectivity in a $135 \mathrm{~mm}$ square mesh trawl in a trouser trawl experiment. Selectivity is measured separately for each haul, e.g. model A.

\begin{tabular}{rcccccc}
\hline \hline Haul & $\mathrm{a}$ & $\mathrm{b}$ & $\mathrm{p}$ & $\mathrm{L}_{25}$ & $\mathrm{~L}_{50}$ & $\mathrm{~L}_{75}$ \\
\hline 7 & $-17.36(1.91)$ & $0.33(0.04)$ & $0.51(0.06)$ & $49.34(1.26)$ & $52.67(1.61)$ & $56.01(2.00)$ \\
9 & $-16.56(1.52)$ & $0.33(0.04)$ & $0.33(0.06)$ & $46.86(1.26)$ & $50.19(1.57)$ & $53.52(1.91)$ \\
13 & $-16.84(1.27)$ & $0.31(0.03)$ & $0.76(0.08)$ & $51.41(2.02)$ & $55.00(2.32)$ & $58.59(2.64)$ \\
14 & $-21.79(1.69)$ & $0.40(0.04)$ & $0.51(0.08)$ & $51.62(1.22)$ & $54.36(1.42)$ & $57.10(1.64)$ \\
15 & $-12.53(1.09)$ & $0.23(0.03)$ & $0.43(0.11)$ & $49.49(2.86)$ & $54.24(3.41)$ & $59.00(3.98)$ \\
\hline
\end{tabular}

TABLE 2B. Parameter estimates and standard errors (in parentheses) for cod size selectivity in a $135 \mathrm{~mm}$ square mesh trawl in a trouser trawl experiment. Selectivity is measured jointly for all hauls but splits are measured separately, e.g. model B.

\begin{tabular}{cccccccccc}
\hline \hline $\mathrm{a}$ & $\mathrm{b}$ & $\mathrm{p}_{7}$ & $\mathrm{p}_{9}$ & $\mathrm{p}_{13}$ & $\mathrm{p}_{14}$ & $\mathrm{p}_{15}$ & $\mathrm{~L}_{25}$ & $\mathrm{~L}_{50}$ & $\mathrm{~L}_{75}$ \\
\hline $\begin{array}{r}-16.00 \\
(0.57)\end{array}$ & 0.29 & 0.40 & 0.53 & 0.55 & 0.57 & 0.72 & 50.74 & 54.48 & 58.22 \\
\hline
\end{tabular}

TABLE 2C. Parameter estimates and standard errors (in parentheses) for cod size selectivity in a 135 $\mathrm{mm}$ square mesh trawl in a trouser trawl experiment. Selectivity and splits are measured jointly for all hauls, e.g. model C.

\begin{tabular}{cccccc}
\hline \hline $\mathrm{a}$ & $\mathrm{b}$ & $\mathrm{p}$ & $\mathrm{L}_{25}$ & $\mathrm{~L}_{50}$ & $\mathrm{~L}_{75}$ \\
\hline-16.30 & 0.30 & 0.55 & 50.61 & 54.27 & 57.93 \\
$(0.57)$ & $(0.01)$ & $(0.04)$ & $(0.80)$ & $(0.94)$ & $(1.09)$ \\
\hline
\end{tabular}

\section{Discussion}

The primary utility of the modelling procedures presented here is in analyzing multiple subsampled hauls with possibly different selectivity and splits. Statistical procedures (graphical and analytical) are developed to assist selectivity researchers in developing parsimonious models. The usual procedure of scaling catches by subsampling fractions is dis- 


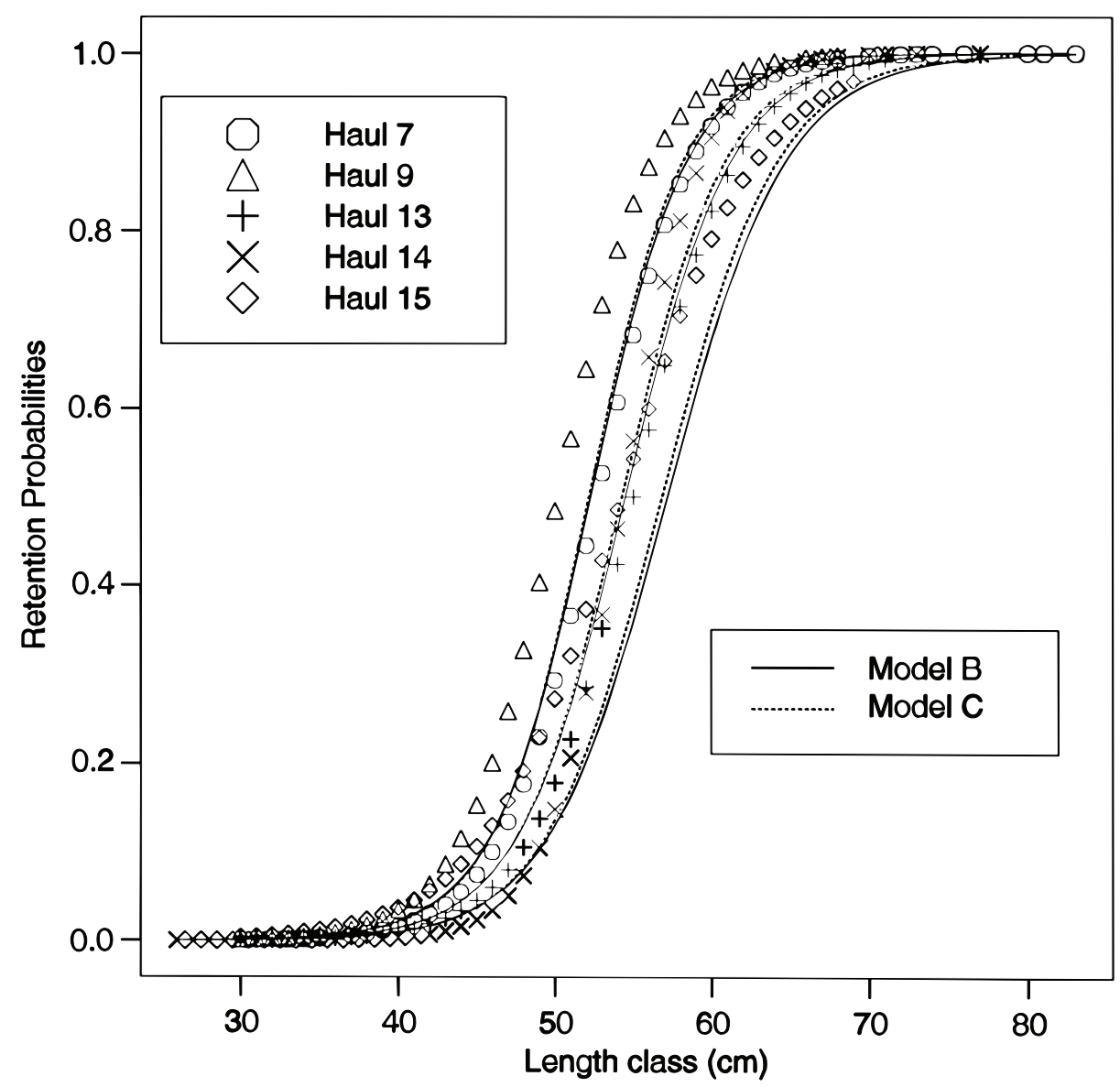

Fig. 1. Estimated selectivity of cod in a $135 \mathrm{~mm}$ square mesh trawl in a trouser trawl experiment assuming common splits (dotted line) and hauls specific splits (solid line). The 95\% upper and lower confidence bounds are drawn with the same line types. The estimated selectivities from each haul are plotted.

couraged because this procedure lacks statistical rigor and will result in invalid inferences, especially if the subsampling fractions are imprecise. Quite often in gear selectivity studies it is difficult to get accurate measurements of the total catch (used in computing subsampling fractions), hence, the procedures developed here offer greater improvements in that a common selectivity from multiple subsampled hauls with imprecise or no subsampling fractions can be estimated in a more sensible statistical procedure.

The data analysis illustrates some of the utility of the methods. However, the analysis is not perfect. The residual plots (Fig. 2) suggest more of the variation is due to between-haul variation in selectivity, however, the between-haul variation in splits is not small. The magnitude of the likelihood ratio test statistics seems to reflect the relative importance of the two sources of variation (2:1). Because of the variability in selectivity (Fig. 1), it is a good idea to base statistical inferences on the haul by haul analyses. It is desirable to estimate a common selectivity, especially when testing differences in gear types (square and diamond meshes), so future extensions in the direction of Fryer (1991) may lead to improved estimation procedures. Similar extensions for variable splits could be considered, however, because these are nuisance parameters and because the procedures developed here are applicable to subsampled catches without subsampling fractions it is not clear that this would yield significant improvements. 
A
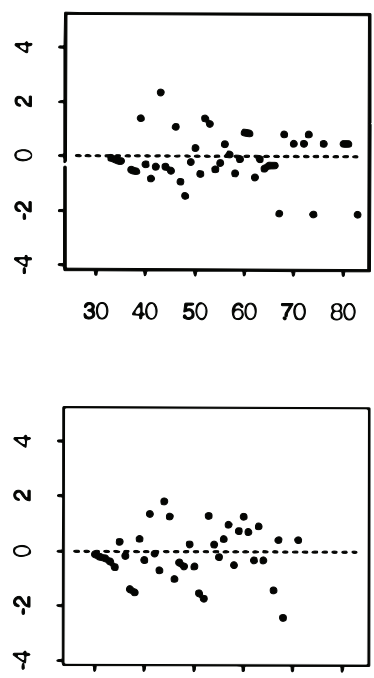

$\begin{array}{llllll}30 & 40 & 50 & 60 & 70 & 80\end{array}$
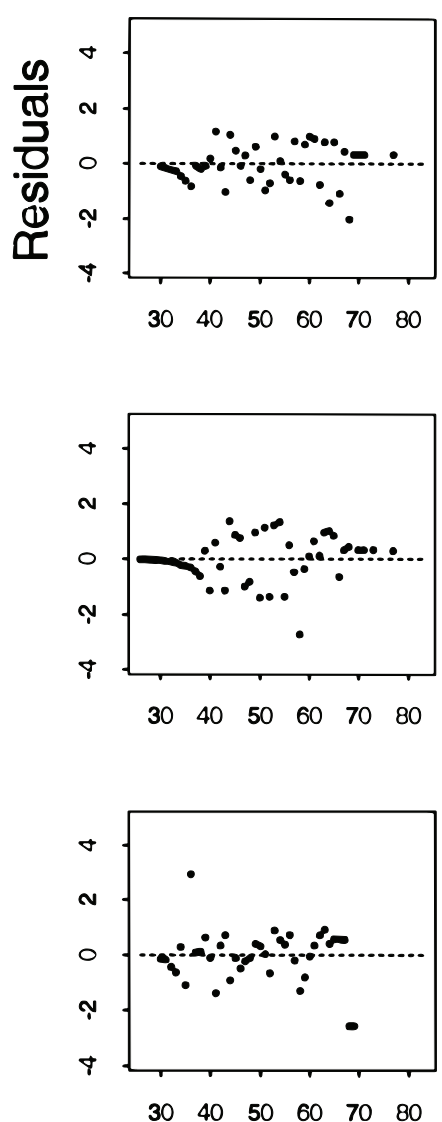

Model

B

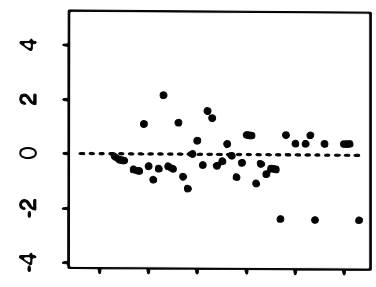

$30 \quad 40 \quad 50 \quad 60 \quad 70 \quad 80$

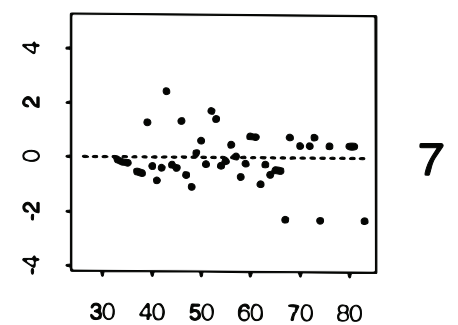

$\begin{array}{llllll}30 & 40 & 50 & 60 & 70 & 80\end{array}$

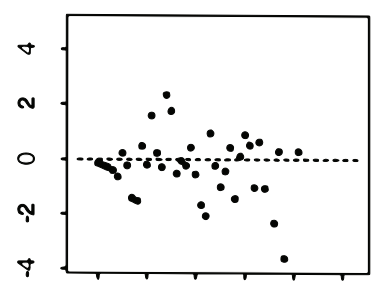

$\begin{array}{llllll}30 & 40 & 50 & 60 & 70 & 80\end{array}$

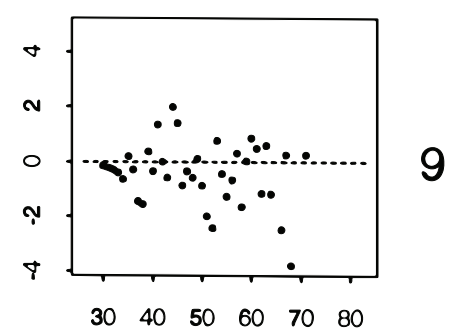

$\begin{array}{llllll}30 & 40 & 50 & 60 & 70 & 80\end{array}$

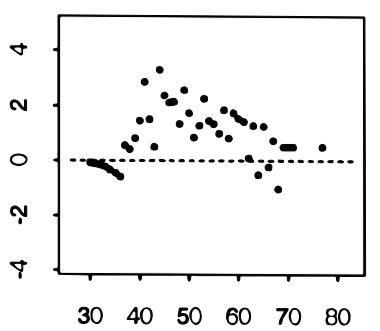

$13 \overline{\bar{\sigma}}$
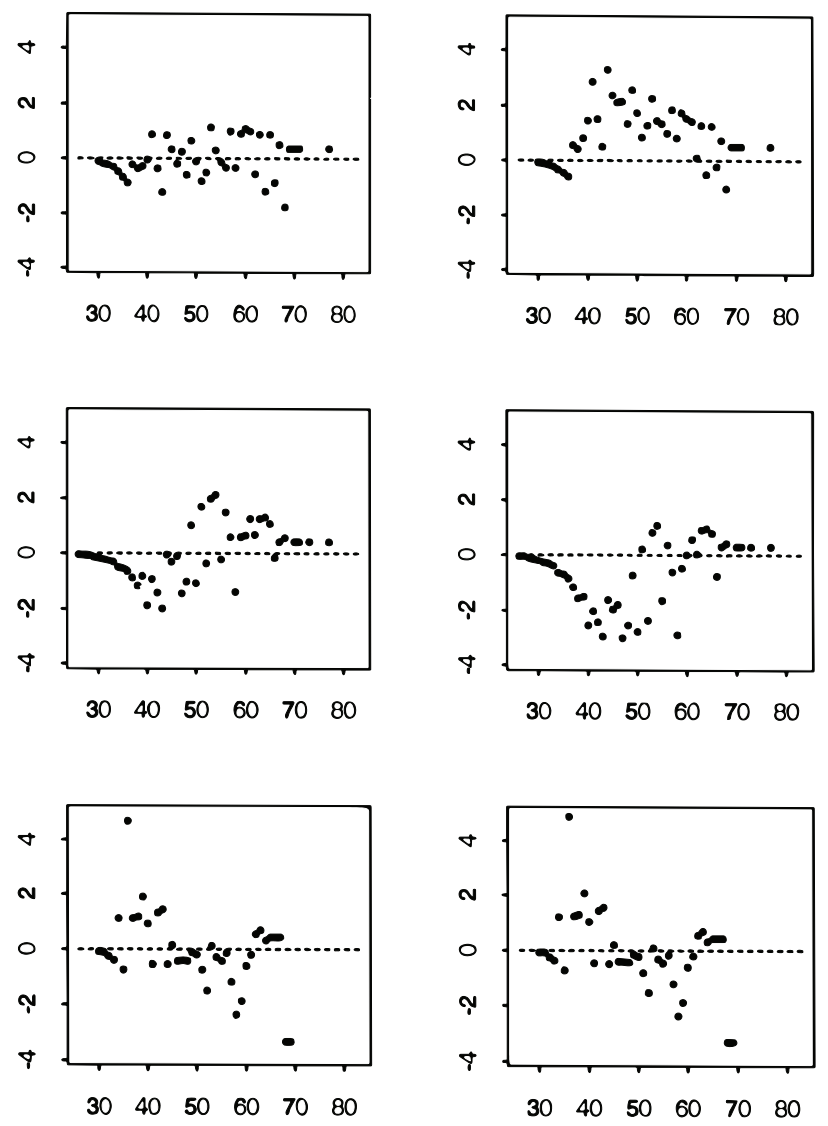

15

Fig. 2. Pearson residuals (observed minus expected divided by the standard deviation) from each model fit and for each haul. The residuals should be roughly homogeneously distributed within \pm 2 . 


\section{References}

CADIGAN, N. G., and R. B. MILLAR. 1992. The reliability of selection curves obtained from trouser trawl or alternative haul studies. Can. J. Fish. Aquat. Sci., 49: 1624-1632.

COOPER, C. G., and W. M. HICKEY. 1989. Selectivity experiments with square mesh codends of 135,140 and $155 \mathrm{~mm}$. Fisheries Development and Fisherman's Services Division Project Report 154, $29 \mathrm{p}$.

FRYER, R. J. 1991. A model of between-haul variation in selectivity. ICES J. Mar. Sci., 48: 281-290

GRAYBILL, F. A. 1976. Theory and application of the linear model. Wadsworth Publishing Company Inc., Belmount, California.

MCCULLAGH, P., and J. A. NELDER. 1989. Generalized linear models. Chapman and Hall, New York.

MILLAR, R. B. MS 1991. Estimating the size-selectivity of fishing gear by conditioning on the total catch: the SELECT (Share Each Length class's Catch Tool) model. ICES C. M. Doc., No. B:57.
1992. Estimating the size selectivity of fishing gear by conditioning on the total catch. J. Amer. Stat. Assoc., 87: 962-968.

MILLAR, R. B., and N. G. CADIGAN. 1991. A FORTRAN program for fitting selectivity curves to trouser trawl data. Can. Tech. Rep. Fish. Aquat. Sci., 1783: iii + 19 p.

MILLAR, R. B., and S. J. WALSH. 1992. Analysis of trawl selectivity studies with an application to trouser trawls. Fish. Res., 13: 205-220.

POPE, J. A., A. R. MARGETTS, J. M. HAMLEY, and E. F. AKYUZ. 1975. Manual of methods for fish stock assessment, Part III. Selectivity of fishing gear. FAO Fish. Tech. Paper, 41, 65 p.

SUURONEN, P., and R. B. MILLAR. 1992. Size selectivity of diamond and square mesh codends in pelagic herring trawls: only small herring will notice. Can. J. Fish. Aquat. Sci., 49: 2104-2117.

WALSH, S. J., R. B. MILLAR, C. G. COOPER, and W. M. HICKEY. 1992. Codend selection in American plaice: diamond versus square mesh. Fish. Res., 13: 235254. 
